\title{
Kasvinkasvumalli täsmäviljelyyn
}

Mikko Hakojärvi ja Mikko Hautala

Helsingin Yliopisto, Agroteknologian laitos, Koetilantie 3, 00014 Helsingin Yliopisto, mikko.hakojarvi@helsinki.fi mikko.hautala@helsinki.fi

\section{Tiivistelmä}

Nykyään on saatavilla huomattava määrä teknologiaa helpottamaan viljelijän työtä peltoviljelyn eri työvaiheissa tai parantamaan työntarkkuutta. Uudesta teknologiasta saatava hyöty kuitenkin riippuu siitä miten ja milloin tätä teknologiaa käytetään. Jotta saatava hyöty olisi mahdollisimman suuri, on teknologiaa pystyttävä käyttämään oikeassa paikassa oikeaan aikaan. Jotta tämä olisi mahdollista, tarvitaan tietoa mm. maaperän ominaisuuksista ja viljelykasvin kasvuvaiheesta ja kehityksestä nykyhetkellä ja lähitulevaisuudessa. Maaperän ja kasvin nykyinen tila voidaan saada selville mittaamalla ja tulevaisuuden tarpeet voidaan saada selville esim. kasvimallin avulla.

Nykyiset kasvimallit ovat hyvin kehittyneitä ja kykenevät ottamaan huomioon suuren joukon kasvin kasvuun vaikuttavia tekijöitä. Tästä syystä ne tarvitsevat toimiakseen paljon informaatiota viljelykasvista ja kasvuolosuhteista kasvukauden aikana. Jotta tälläistä kasvimallia voidaan hyödyntää, tarvitaan erittäin paljon paikkakohtaisia mittauksia yhden peltolohkon sisällä. Mittausdatan keruuta mallin vaatimassa mittakaavassa on erittäin hankala järjestää. Täsmäviljelyssä hyödynnettävien mallien tuleekin olla riittävän yksinkertaisia, jotta mitattavien suureiden määrä ei kasva paikkakohtaisessa käytössä kohtuuttoman suureksi. Toisaalta yksinkertaistenkin mallien tulee olla riittävän monimutkaisia ja laajoja, jotta ne kykenevät kuvaamaan kasvin kasvua, kehitystä ja tarpeita kasvukauden aikana

Tutkimuksessamme olemme kehittäneet mallin kuvaamaan viljelykasvin biomassan kertymistä em. vaatimukset huomioon ottaen. Jotta mallit olisivat käytettävissä ilman paikkakohtaista kalibrointia, ei parametreihin saa sisältyä paikkaan tai olosuhteisiin sidottua informaatiota. Tästä syystä kaikilla mallissamme käytetyillä parametreilla on selkeä fysikaalinen, kemiallinen tai fysiologinen perusta. Koska halusimme testata mallimme paikkansapitävyyttä käytännössä, suoritimme kasvukaudella 2009 paikkakohtaisia mittauksia pelto-olosuhteissa. Koealueelta mitattiin kasvin kasvuun vaikuttavia tekijöitä kolmesta eri pisteestä, joissa yhdessä kasvoi syysvehnää ja kahdessa muussa kevätvehnää. Mitattuja suureita olivat: maan kosteuspitoisuus, lämpötila sekä maassa että ilmassa, maaveden potentiaali, PAR säteily, kokonaissäteily ja ilmankosteus. Kasvustosta puolestaan mitattiin jatkuvana mittauksena lehtialan kehitystä. Alustavien vertailujen perusteella yksinkertaisillakin analyyttisillä malleilla on mahdollista saavuttaa varsin tarkkoja tuloksia maan kosteuspitoisuudesta ja kasvin biomassasta. Mitä tarkoittaa jatkossa?!

Asiasanat: täsmäviljely, biomassa, kasvimalli, mittaus 


\section{Johdanto}

Viime vuosikymmeninä viljelijöiden työtaakka on helpottunut ja vähentynyt koneiden, teknologian ja automaation kehittyessä. Tuotantomenetelmien ja koneiden kehitettämistä on jatkettava edelleen, jotta vastaava kehitys on mahdollista myös tulevaisuudessa. Tämän kehityksen myötä automaation määrä käytettävissä koneissa tulee lisääntymään ja vähitellen johtamaan itsenäisesti toimiviin ja täysin automaattisiin koneisiin. Tällainen tekniikka mahdollistaa viljelykasvin kasvuolosuhteiden pitämisen optimaalisina entistä tarkemmin aina kylvöstä sadonkorjuuseen viljelijän tekemän työn määrää kuitenkaan lisäämättä. Tällaiseen tilanteeseen pääsemiseen tarvitaan uusien teknologioiden lisäksi tietoa kasvuolosuhteista. Tietoa kasvusta ja kasvustosta tarvitaan kylvöstä aina sadonkorjuuseen asti, mikä edellyttää joko paljon yksittäisiä mittauksia tai jatkuvaa mittausta pellolta. Eri viljelytoimenpiteet voidaan mitatun tiedon avulla ajoittaa oikeaan aikaan ja samalla voidaan varmistaa, että toimenpiteen suorittavat koneet eivät aiheuta pellolla maaperän tiivistymistä. Yksistään mitattu tieto ei kuitenkaan vielä riitä päätöksentekoon, sillä nykyhetkellä mitatusta tilasta pitää pystyä ennustamaan kasvin tarvetta esim. vedelle ja ravinteille. Online-mittausten lisäksi tarvitaan viljelykasvin kasvua kuvaava malli, joka kykenee mittausten perusteella ennustamaan kasvin lähitulevaisuuden tarpeita, mutta on riittävän yksinkertainen täsmäviljelyyn eli käytettäväksi paikkakohtaisesti peltolohkoilla.

Pelto-olosuhteissa kasvin kasvuun vaikuttavat tekijät, kuten maan ominaisuudet, auringon paiste ja mikro-ilmastolliset olosuhteet vaihtelevat sekä ajasta että paikasta riippuen [4].. Peltoa tuleekin tämän vuoksi käsitellä heterogeenisenä alueena, jossa olosuhteet vaihtelevat paikasta riippuen. Käytännössä suurin osa olemassa olevista kasvin kasvumalleista on tehty simuloimaan kasvin kasvua pistemäisesti eli yhdessä paikassa, mistä johtuen siirtyminen paikkakohtaisen kasvun mallinnukseen tarkoittaa muutoksia itse mallin rakenteeseen, jotta spatiaaliset riippuvuudet voidaan ottaa mallissa huomioon [5]. Pisimmälle kehittyneiden kasvimallien tarjoaman kapasiteetin hyödyntäminen kokonaan tarkoittaisi valtavaa määrää paikkakohtaisia mittauksia yksittäiseltä peltolohkolta. Pellolta kerättävän tiedon määrää on mahdollista pienentää ottamalla mallissa huomioon vain kasvun kannalta tärkeimmät prosessit, menettämättä kuitenkaan olennaista dynamiikkaa kasvin kasvun kuvauksessa [6]. Nämä tekijät yhdessä pellon ominaisuuksien spatiaalisen vaihtelun ja työkoneiden leveyksien kanssa muodostavat tarvittavan spatiaalisen resoluution pellosta kerättävälle informaatiolle.

Tutkimuksemme keskeisenä ajatuksena on ollut yksinkertaisen kasvimallin ja maaperämallin kehittäminen. Laaditun mallin tarkoitus ei ole ollut jäljitellä viljelykasvien kasvua tai veden liikkumista maassa mahdollisimman tarkasti, vaan tavoitteena on ollut realistiset mallit viljelykasvin biomassan kertymiselle ja maaperän veden liikkumiselle mahdollisimman pienellä määrällä parametreja.. Mallin on tarkoitus toimia automaattisen kasvinviljelyn simuloinnin perustana. Tässä esityksessä esitellään alustavia vertailuja mallin antamista tuloksista ja peltomittauksista.

\section{Kasvimalli}

Tutkimuksessamme kehittämä kasvinkasvumalli on yksinkertainen, avoin, analyyttinen ja kuvaa C3kasvien biomassan kertymistä [7,8] (Kuva 1). Tässä esitelmässä esitetään mallin yksinkertaisin muoto eli analyyttinen malli [9]. Yksityiskohtaisempia simulointimalleja on kuvattu aikaisemmin julkaistuissa artikkeleissa [7,8]. Tulevissa kappaleissa käydään tarkemmin läpi mallin avainkohtia ja keskeisimpiä mallissa käytettyä oletuksia ja mallin parametreihin vaikuttavia arvoja ja laskentakaavoja. 


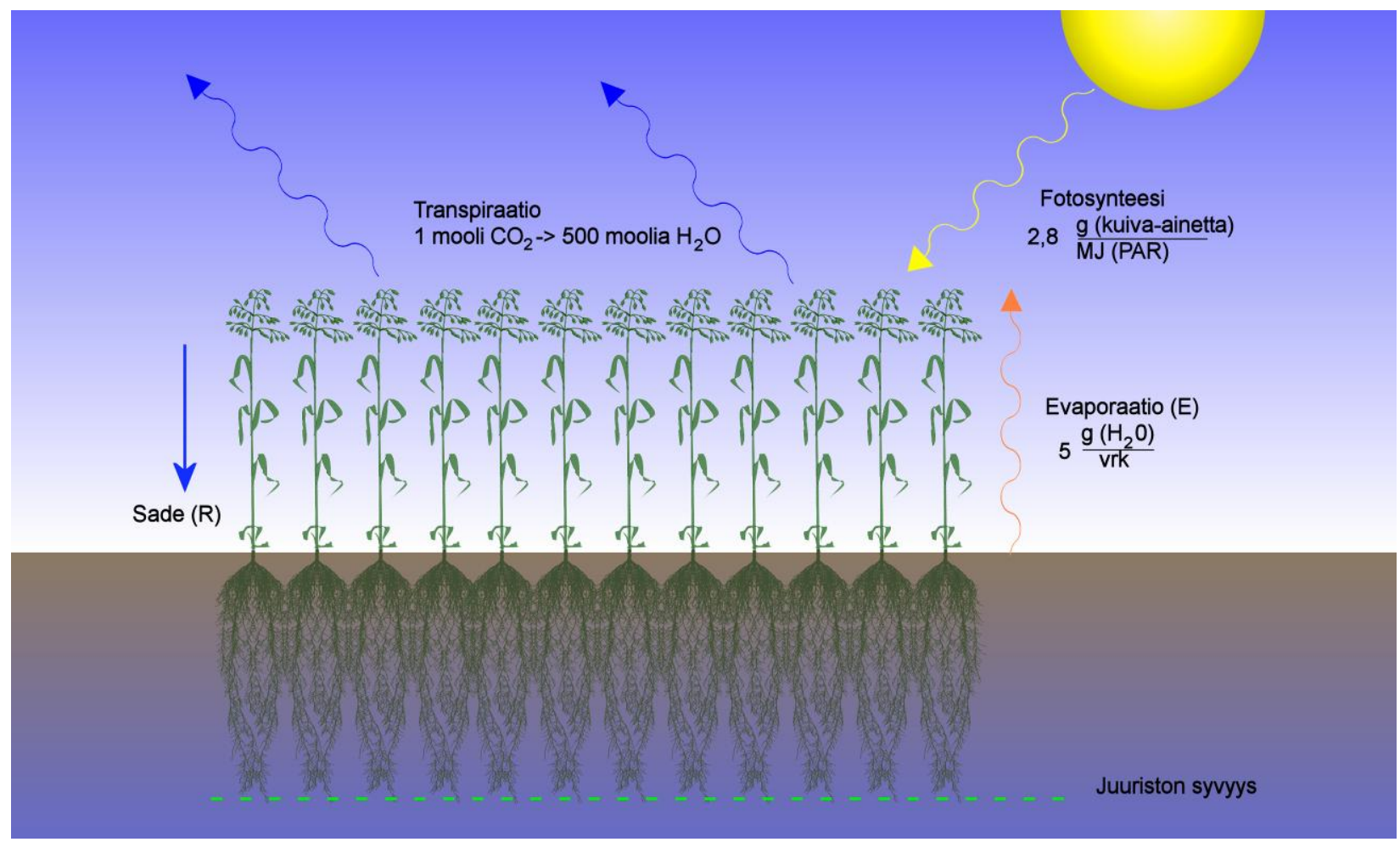

Kuva 1. Mallissa kasvin kasvuun vaikuttavia tekijöitä.

\section{Kasvun edellytykset}

Mallissamme kasvin kasvua oletetaan rajoittavan vain veden määrä ja auringon säteily. Oletuksena on, että lämpötila on kasvamiselle optimaalinen, ravinteita on riittävästi, eivätkä rikkakasvit tai taudit haittaa kasvua. Jotta malli voidaan saattaa analyyttiseen muotoon, on arvoja eri parametreille vakioitava. Tämä tarkoittaa, että mm. transpiraatiolle (WUE), fotosynteesille (RUE) ja lehtien osuudelle koko kasvin biomassasta (LWR) on vakioitava tietyt parametrit. Säteilyn vastaanotossa oletetaan yksittäisen lehden kykenevän sitomaan vain tietyn osan fotosynteesiin käytettävissä olevasta säteilystä. Siitä johtuen oletetaan, että kaiken fotosynteettisesti aktiivisen säteilyn (I) vastaanottaminen edellyttää tiettyä lehtialaindeksiä (LAI). Vastaanotetun säteilyn oletetaan kasvattavan biomassaa tietyn määrän [10]. Tässä mallissa transpiraatiolla tarkoitetaan kasvin menettämä veden määrä lehtien ilmaraoista kaasunvaihdon yhteydessä. Kasvi joutuu avaamaan lehtiensä ilmaraot saadakseen yhteyttämiseen tarvittavaa hiilidioksidia ja luovuttaakseen yhteyttämisen tuloksena syntynyttä happea. Ilmarakojen sisäpinnat puolestaan ovat kosteat, mistä johtuen rakojen avautuessa aiheutuu veden haihduntaa, joka on suuruudeltaan 500 moolia $\mathrm{H}_{2} \mathrm{O}$ jokaista vastaanotettua moolia $\mathrm{CO}_{2}$ :ta kohden [11]. Kun kasvilla on riittävästi vettä saatavillaan, ei tällä ilmiöllä ole vaikutusta kasvin kasvuun, vaan säteilyn määrä rajoittaa kasvin kasvua.

\section{Lehtiala ja säteilyn rajoittama kasvu}

Kun kasvua rajoittaa säteilyn määrä tai lehtiala, tarvitaan malliin kuusi parametria: biomassa alkuhetkellä (yhden taimen massa $\left(\mathrm{m}_{\mathrm{s}}\right) \times$ taimitiheys $(\mathrm{SD})$ ), lehden pinta-ala jaettuna lehden massalla (SLA,), lehtien osuus kasvin koko biomassasta (LWR), päivittäinen fotosynteettisesti aktiivisen säteilyn määrä (PAR), säteilyn käytön tehokkuus (RUE) ja säteilyn suurin intensiteetti, minkä lehti voi hyödyntää ( $\mathrm{I}_{\text {sat }}$ ). Malli kuvaa kasvin kasvua siitä lähtien, kun siemen on täysin taimettunut ja kaava biomassan kertymiselle tässä kasvun vaiheessa on melko yksinkertaisesti johdettavissa [9]: 


$$
\begin{aligned}
& B M(t)=B M(0) \cdot e^{K \cdot t}=m_{s} \cdot e^{K \cdot t}, \text { kun } L A I<\frac{I}{I_{\text {sat }}} \text { ja } t<t_{o} \\
& L A I(t)=B M(t) \cdot L W R \cdot S L A \\
& K=R U E \cdot I_{\text {sat }} \cdot L W R \cdot S L A \\
& t_{0}=\ln \left(\frac{I / I_{\text {sat }}}{L A I(0)}\right) / K
\end{aligned}
$$

$\mathrm{BM}(\mathrm{t})$ on kasvin koko biomassa neliömetriä kohti hetkellä t. Ajanhetkestä $\mathrm{t}_{0}$ lähtien kasvi kykenee hyödyntämään kaiken tulevan fotosynteettisesti aktiivisen säteilyn, jolloin kasvu muuttuu eksponentiaalisesta lineaariseksi. Tällöin biomassan kertymiselle saadaan kaava:

$$
B M(t)=B M\left(t_{0}\right)+R U E \cdot I \cdot\left(t-t_{o}\right), \quad \text { kun } L A I>\frac{I}{I_{\text {sat }}} \text { ja } t>t_{o} .
$$

Tämän ajanjakson aikana kasvu riippuu yksistään säteilyn määrästä (I · n). Suurentamalla lehtialaansa kasvi ei enää voi lisätä kasvuaan, koska kaikki tuleva säteily on jo kasvi käytettävissä ja lehtialan kasvun myötä lehdet varjostaisivat toisiaan entistä enemmän. Tämän jakson jälkeenkin malli kuvaa kasvin biomassan kertymistä niin pitkään kunnes lehtiala alkaa vähentyä, sillä laskuissa BM edustaa kasvin koko biomassan määrää. Kaavat 1 ja 2 antavat kasvin hetkittäisen biomassan $\left(\mathrm{kg} / \mathrm{m}^{2}\right)$ käytettäessä taulukon 1 arvoja.

\section{Veden rajoittama kasvu}

Optimaalisissa kasvuolosuhteissa kaavat 1 ja 2 antavat biomassan kasvun jyvän täyttymisen alkuun asti, jos vesi ei rajoita kasvin kasvua. Kun halutaan huomioida myös veden vaikutus kasvuun täytyy malliin ottaa mukaan viisi parametria lisää: vedenkäytön tehokkuus (WUE), juurten kasvunopeus ( $\mathrm{r}_{\text {growth }}$ ), juuriston suurin mahdollinen syvyys $\left(\mathrm{r}_{\max }\right)$ sekä maan kosteusrajat: kenttäkapasiteetti (FC) ja lakastumisraja (PWP). Kun vesi on kasvua rajoittava tekijä, se määrää päivittäisen biomassan kasvun. Kasvilla käytettävissä olevan veden määrään vaikuttavat suuresti sade $(R)$ ja evaporaatio (E), jotka määräävät maaprofiiliin saapuvan ja sieltä poistuvan veden määrän. Kun vesi on päässyt maaperään, sen käyttökelpoisuuden kasville määrittävät kasvin juuret:

$B M(t)=\left[(F C-P W P) \cdot r_{\text {depth }}(t)+t \cdot(R-E)\right] \cdot \rho_{\text {water }} \cdot W U E \cdot \frac{M_{g l c}}{M_{\mathrm{CO}_{2}}}$

$B M\left[\frac{\mathrm{kg}}{\mathrm{m}^{2}}\right]=$ käytettävissä oleva vesi $[\mathrm{m}] \cdot$ veden tiheys $\left[\frac{\mathrm{kg}}{\mathrm{m}^{3}}\right] \cdot W U E\left[\frac{\mathrm{g}_{\mathrm{CO}_{2}}}{\mathrm{~g}_{\mathrm{H}_{2} \mathrm{O}}}\right] \cdot$ moolimassa $\left[\frac{\mathrm{g}_{\mathrm{glc}}}{\mathrm{g}_{\mathrm{CO}_{2}}}\right]$.

Kaavassa 3 suluissa oleva osa kertoo kasvilla päivittäin käytettävissä olevan veden määrän, minkä maan ominaisuudet (FC, PWP), pinnan ilmiöt $(\mathrm{R}, \mathrm{E})$ ja juuristo $\left(\mathrm{r}_{\text {depth }}\right)$ rajoittavat. $\mathrm{M}_{\mathrm{GLC}}$ on yhteyttämisen lopputuloksena syntyvän glukoosin moolimassa $(\mathrm{g} / \mathrm{mol}) \mathrm{ja} \mathrm{M}_{\mathrm{CO} 2}$ on vastaavasti yhteyttämisessä kuluvan hiilidioksidin moolimassa. Maaperässä vesi on kasvin saatavilla, kun maan kosteuspitoisuus on lakastumisrajan ja kenttäkapasiteetin välissä. Kenttäkapasiteetin ylittävän kosteuden oletetaan liikkuvan maassa niin nopeasti juurten ohi, että se ei ole kasville käyttökelpoista. Malli ei tällaisenaan kykene ottamaan huomioon tilanteita, joissa kasvin juuret ylettävät pohjaveteen tai maa kykenee voimakkaasti nostamaan pohjavettä juurten alueelle kapillaarisuuden avulla. Sekä säteilyn että veden rajoittaman kasvun kaavojen parametrien arvot esitetään taulukossa 1. Huomattavaa parametreissa on, että ne kaikki ovat joko mitattavissa tai niillä on fysikaalinen perusta. 
Taulukko 1. Arvoja parametreille säteilyn tai veden rajoittamaan kasvuun.

\begin{tabular}{|c|c|c|c|}
\hline Parametri & Lyhenne & Arvo & Yksikkö \\
\hline \multicolumn{4}{|l|}{ Säteilyn ja lehtialan rajoittama kasvu } \\
\hline Säteilyn käytön tehokkuus & RUE & $2.8 \times 10^{-9}$ & $\mathrm{~kg} / \mathrm{J}$ \\
\hline Tuleva PAR säteily & I & 250 & $\mathrm{~W} / \mathrm{m}^{2}$ \\
\hline Lehden kyky käyttää säteilyä & $\mathrm{I}_{\text {sat }}$ & 100 & $\mathrm{~W} / \mathrm{m}^{2}$ \\
\hline Taimien tiheys & SD & 500 & taimea $/ \mathrm{m}^{2}$ \\
\hline Lehden pinta-ala jaettuna lehden massalla & SLA & 20 & $\mathrm{~m}^{2} / \mathrm{kg}$ \\
\hline Yksittäisen taimen massa & $\mathrm{m}_{\mathrm{s}}$ & 40 & $\mathrm{mg}$ \\
\hline Lehtien osuus biomassasta & LWR & 0.5 & \\
\hline Päivittäinen säteilyn kesto & $\mathrm{n}$ & 10 & $\mathrm{~h}$ \\
\hline \multicolumn{4}{|l|}{ Veden rajoittama kasvu } \\
\hline Veden käytön tehokkuus & WUE & 0.0008 & $\mathrm{~g}_{\mathrm{CO} 2} / \mathrm{g}_{\mathrm{H} 2 \mathrm{O}}$ \\
\hline Kenttäkapasiteetti & $\mathrm{FC}$ & 0,37 & $\mathrm{~m}^{3} / \mathrm{m}^{3}$ \\
\hline Lakastumisraja & PWP & 0,14 & $\mathrm{~m}^{3} / \mathrm{m}^{3}$ \\
\hline Päivittäinen juuren kasvu & $\mathrm{r}_{\text {growth }}$ & 0,02 & $\mathrm{~m} / \mathrm{d}$ \\
\hline Juuriston suurin mahdollinen syvyys & $\mathrm{r}_{\max }$ & 1,0 & $\mathrm{~m}$ \\
\hline
\end{tabular}

Käytännössä kaavat biomassan kertymiselle sisältävät vain kolme toisistaan riippumatonta termiä: kasviriippuvainen parametri (SLA), agronominen termi $\left(\mathrm{m}_{\mathrm{s}}\right)$ ja paikkakohtainen termi (I $\mathrm{n}$ ). Vaikutuksellisesti malli sisältää kuusi parametria säteilyn rajoittamaan kasvuun ja neljä lisää veden rajoittaman kasvun laskemiseen, koska kenttäkapasiteetti ja lakastumisraja yhdessä määrittävät kasville käyttökelpoisen veden.

\section{Kasvukaudella 2009 tehdyt mittaukset}

Kasvukaudella 2009 teimme paikkakohtaisia mittauksia kahdessa eri kasvupaikassa, joissa toisessa kasvoi kevätvehnää ja toisessa syysvehnää. Pyrimme kasvukauden aikana mittaamaan kasvien kasvun kannalta relevantteja ominaisuuksia erilaisia antureita käyttäen. Kasvukauden aikana mitattiin mm. lehtialaindeksiä, SLA:ta, tulevan säteilyn määrää, ilman kosteutta, ilman lämpötilaa, kasvuston lämpösäteilyä, sekä maan veden potentiaalia, kosteuspitoisuutta ja lämpötilaa.

\section{Tulokset}

Kasvin juurten kasvua ja vedenoton vaikutusta maan kosteuspitoisuuteen pystyttiin havainnoimaan hyvin $30 \mathrm{~cm}: n$ syvyyteen asetetun anturin tuloksista (Kuva 2). Hyvin lähelle maan pintaa sijoitettujen anturien mittaustuloksista voidaan puolestaan havaita evaporaation aikaansaamat, nopeammat kosteuspitoisuuden muutokset.l Kun tarkastellaan 20 ja $30 \mathrm{~cm}: n$ syvyyteen sijoitettuja antureita, havaitaan, että kosteuspitoisuudet eivät koskaan mittausjakson aikana nousseet pidemmäksi aikaa 37\%:a korkeammalle. Tämän kosteuden voidaan olettaa vastaavan kenttäkapasiteettia. Vastaavasti kosteus ei myöskään laskenut alle 20\%:n kosteuden, jonka voidaan olettaa olevan lakastumisraja. Pintamaahan sijoitettujen antureiden mittaustulosten perusteella kasvukauden 2009 kevät oli kuiva. Kevään kuivuus vaikutti myös viljelykasvin kasvuun rajoittamalla kasvin kasvua varhaisessa vaiheessa (Kuva 3). 


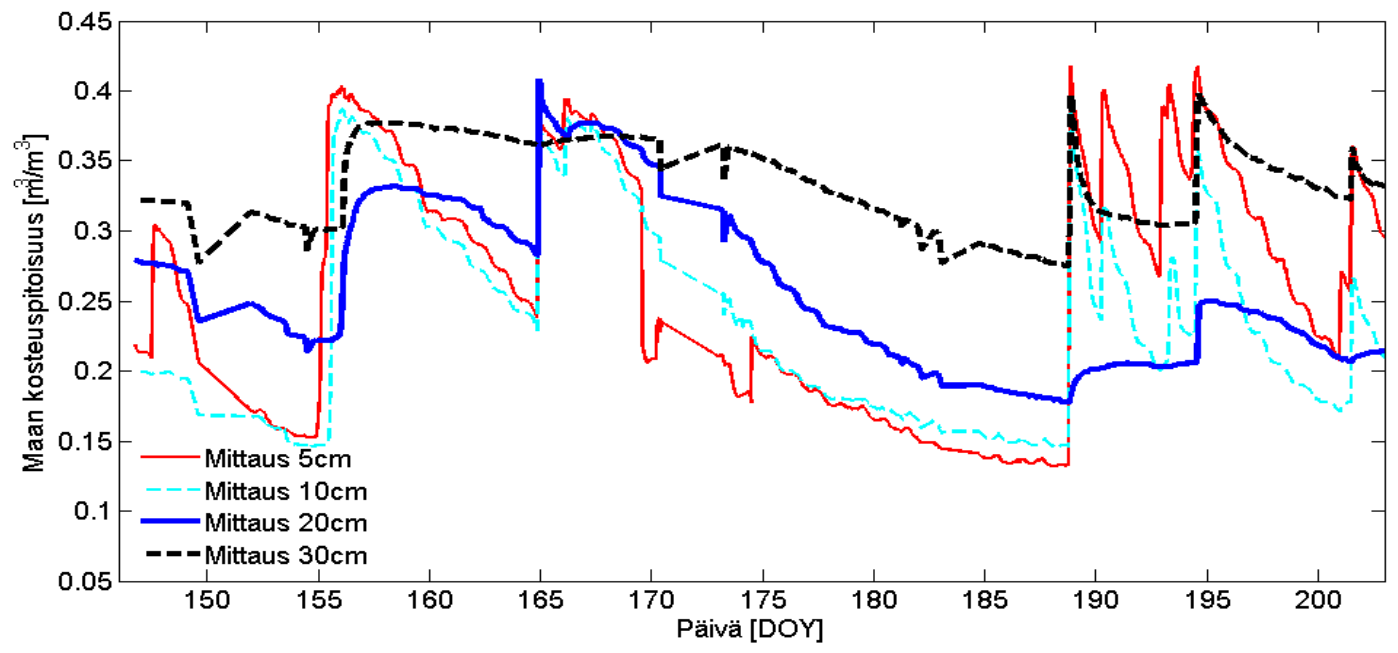

Kuva 2. Maan kosteuspitoisuuden mittaustuloksia eri syvyyksiltä syysvehnäkasvustosta.

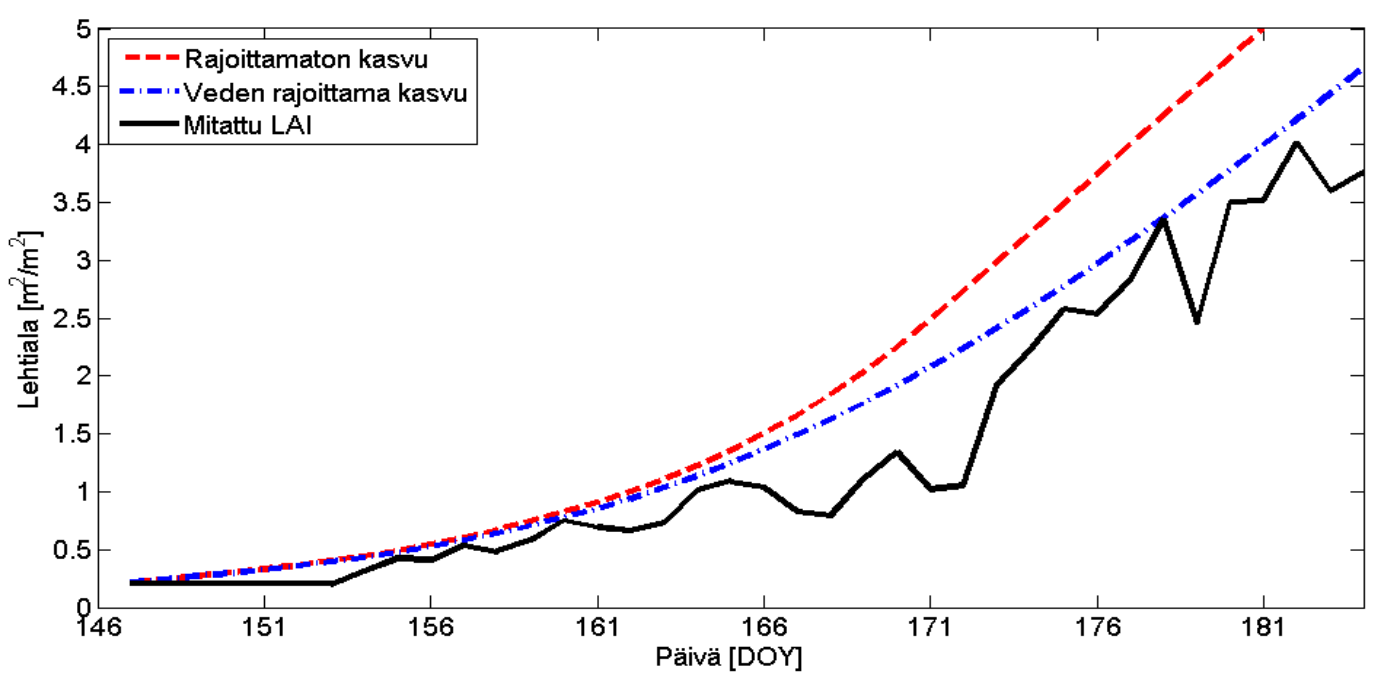

Kuva 3. Mitattu ja simuloitu lehtialan kehitys kasvukauden alussa kevätvehnäkasvustosta.

Viljelykasvin lehtialan kehityksestä on selvästi nähtävissä kasvun viivästyminen vedenpuutteen takia (Kuva 3). Kasvukauden edetessä viljelykasvin lehtialan kertyminen hidastuu ja se saavuttaa lopulta arvon neljä. Tämän jälkeen lisääntyvä biomassa kertyy kasvissa varteen ja myöhemmin jyvään. Kaavassa 1 biomassan oletetaan kertyvän vain lehtiin ja juuriin. Lehtien osuus pitäisi jakaa lehtien, varren ja siementen osuuksiksi, jos haluttaisiin verrata LAI:ta kasvun myöhemmissä vaiheissa. Esim. viljoilla Torjunta- ja lisälannoitustoimenpiteet tulisi kuitenkin suorittaa ennen kukkimista, jolloin viljelytoimenpiteitä ajatellen ajankohdat kukkimisesta eteenpäin eivät ole enää niin kiinnostavia. Mallin simuloiman ja kasvustosta mitatun biomassan vertailu osoittaa lehtialamittausten kaltaista vastaavuutta ja tukee käsitystä siitä, että malli kuvaa riittävän hyvin kasvin kasvua täsmäviljelyn tarpeisiin.

\section{Tulosten tarkastelu ja johtopäätökset}

Esitellyt tulokset sekä meneillään olevat vertailut ovat osoittaneet esitellyn mallin antavan hyvin realistisia tuloksia suhteellisen pienellä määrällä kerättyä informaatiota. Kehittämämme kasvimallin vahvuuksiin kuuluvat parametrit ja niiden läpinäkyvyys. Kaikilla parametreilla on selkeä tausta ja niiden arvot voidaan kasvukauden aikana mitata, mikäli simuloinnin tarkkuutta halutaan lisätä. Poikkeamat mallin parametrien ja pellolta mitattujen arvojen välillä kertovat niiden spatiaalisesta ja temporaalisesta vaihtelusta käytännön 
pelto-oloissa, kun ensin rikkakasvien, kasvitautien tai ravinteiden puutteen mahdolliset vaikutukset on otettu huomioon. Mallin rakenne ja läpinäkyvyys mahdollistavat kasvukauden aikana tehtyjen mittausten hyödyntämisen simuloinnissa, jolloin simulointitulosten tarkkuutta niiden luotettavuutta päätöksenteon apuvälineenä voidaan parantaa. Tällainen rakenne on olennainen mallille, mikäli halutaan pitää kasvustosta ja pellolta tehtävien mittausten määrä kohtuullisena, mutta silti saavuttaa riittävän realistisia simulointituloksia biomassan kertymisestä. Tällaiseen malliin on helposti lisättävissä lisää sadon vaihtelua aiheuttavia tekijöitä, kuten vaihtelut kasvuun vaikuttavissa maaperän ominaisuuksissa lohkon sisällä.

Jo nyt pelloilta saadaan tietoa mm. sadosta korjuun yhteydessä sadonmittauslaitteistolla varustetun puimurin avulla ja maaperästä paikkatietoon sidottujen maanäytteiden avulla. Tällä hetkellä kehitysasteella olevien menetelmien ja tekniikoiden avulla voidaan tulevaisuudessa kerätä pelloilta tietoa normaalien peltotöiden, kuten maan muokkauksen yhteydessä. Koska kaikkia tarvittavia tekijöitä maan ominaisuuksista ei nykyisillä tekniikoilla voida mitata kohtuullisella työmäärällä edes välttävällä spatiaalisella resoluutiolla, voi olla kannattavampaa mitata haluttua ominaisuutta jatkuvasti maahan upotettavilla mittalaitteilla [1-3]. Mittaustekniikasta riippumatta kasvustosta ja pellolta tehtävien mittauksien sekä kasvimallin on tuettava toisiaan, jolloin vältytään ylimääräisiltä tai tarpeettomilta mittauksilta.

Ravinteita ei tähän malliin ole sisällytetty, mutta mallin rakenne mahdollistaa niidenkin huomioimisen kohtuullisen pienellä työmäärällä. Skenaariomme mukaan kylvön yhteydessä pellolle voitaisiin levittää eksponentiaaliseen kasvuun kuluva lannoitemäärä. Myöhemmin kasvukaudella toteutuneen kasvun ja mallin avulla voidaan päättää lisälannoituksen tarve huomioiden kasvukauden olosuhteet. Tämä on olennaista lannoitteen hyödyntämisen kannalta, sillä sademäärä kasvukaudella saattaa vaihdella hyvinkin huomattavasti, esimerkiksi Suomessa aikavälillä 1.4. - 15.7. sadesummat ovat vaihdelleet 20 ja $200 \mathrm{~mm}$ välillä. Vähäsateisella kasvukaudella vesi on kasvua rajoittava tekijä, mistä johtuen kasvi ei kykene hyödyntämään kaikkea sille keväällä annettua lannoitusta, etenkin mikäli lannoitus on mitoitettu korkeaa satotasoa tavoitellen. Skenaariossammen on tavoitteena mahdollisimman suuri sato vallitsevissa sääoloissa ja esitellyllä tavalla voitaisiin varmistaa lannoitteiden päätymistä kasvin käyttöön huuhtoutumisen sijasta.

\section{Kirjallisuus}

[1] Tiusanen, J. 2005. Attenuation of a soil scout radio signal. Biosystems Engineering, 90:127-133.

[2] Tiusanen, J. 2008. Wireless soil scout prototype radio signal reception compared to the attenuation model. Precision Agriculture.

[3] Hautala, M. \& Tiusanen J. 2007. Depth determination of a wireless underground soil scout. Precision agriculture '07, Wageningen, s. 333-339.

[4] Batchelor, W.D., Basso, B. \& Paz, J.O. 2002. Examples of strategies to analyze spatial and temporal yield variability using crop models. European Journal of Agronomy, 18:141-158.

[5] Ferreyra, R.A., Jones, J.W. \& Graham, W.D. 2006. Parameterizing spatial crop models with inverse modeling: Sources of error and unexpected results. Transactions of the ASABE, 49:1547-1561.

[6] Sadler, E.J., Gerwig, B.K., Evans, D.E., Busscher, W.J. \& Bauer, P.J. 2000. Site-specific modeling of corn yield in the SE coastal plain. Agricultural Systems, 64:189-207.

[7] Hakojärvi, M., Hautala, M., Ahokas, J. 2008. Simulation of fully-automatic crop farming in Finland, International Conference on Agricultural Engineering: conference proceedings CD. - Athens : AgEng2008 Conference P094, $10 \mathrm{~s}$.

[8] Hautala, M. \& Hakojärvi, M. 2008. Optimization of subirrigation water level in humid and arid conditions. Journal of Agricultural Machinery Science, 4:117-122.

[9] Hautala, M. \& Hakojärvi, M. 2009. Julkaisematon.

[10] Monteith, J.L. \& Moss, C.J. 1977. Climate and the efficiency of crop production in Britain [and discussion]. Philosophical Transactions of the Royal Society of London. Series B, Biological Sciences, 281:277-294.

[11] Taiz, L. \& Zeiger, E. 1991. Plant Physiology, California, The Benjamin/Cummings Publishing Company, Inc. 